Pesq. Vet. Bras. 36(9):798-804, setembro 2016

DOI: $10.1590 / \mathrm{S} 0100-736 \mathrm{X} 2016000900002$

\title{
Avaliação lectino-histoquímica de fígado e linfonodo mesentérico de búfalos mantidos em pastagens de Brachiaria spp. ${ }^{1}$
}

\author{
Ileana C. Miranda ${ }^{2 *}$, Gabriela Riet-Correa ${ }^{3}$, Carlos A. Oliveira Júnior ${ }^{3}$, Beatriz Riet- \\ Correa ${ }^{4}$, Paulo V. Peixoto ${ }^{5}$, Samay Z.R. Costa ${ }^{6}$, Mariana S. d'Avila², Gabriela C. Cid ${ }^{2}$ \\ e Ticiana N. França ${ }^{7}$
}

\begin{abstract}
Miranda I.C., Riet-Correa G., Oliveira Júnior C.A., Riet-Correa B., Peixoto P.V., Costa S.Z.R., d'Avila M.S., Cid G.C. \& França T.N. 2016. [Lectin histochemistry evaluation of liver and mesenteric lymph node of buffaloes kept on Brachiaria spp. pastures.] Avaliação lectino-histoquímica de fígado e linfonodo mesentérico de búfalos mantidos em pastagens de Brachiaria spp. Pesquisa Veterinária Brasileira 36(9):798-804. Curso de PósGraduação em Medicina Veterinária, Instituto de Veterinária, Universidade Federal Rural do Rio de Janeiro, Campus de Seropédica, BR-465 Km 7, Seropédica, RJ 23890-000, Brazil. E-mail: ileanamiranda@gmail.com

Animals grazing Brachiaria spp. commonly present foamy macrophages isolated or grouped in the liver, and crystals within biliary ducts. The pathogenesis of formation and the nature of the material stored in these cells however are not completely known. Through lectin histochemistry evaluation, steroidal saponins (secondary glycosylated metabolites) have been identified in the crystals and within the cytoplasm of the foam cells, which are probably liable for damaging the liver, leading to accumulation of phylloerythrin. This study aims to standardize and characterize the use of lectin histochemistry to detect glycosylated metabolites in tissues of buffaloes kept on different Brachiaria spp. pastures in Brazil. Fragments of liver and mesenteric lymph node from 40 buffaloes were analyzed: 10 buffaloes that were kept in predominant pasture of B. decumbens for 12 months; 10 buffaloes that were kept in pasture with a predominance of $B$. brizantha for 18 months; 10 buffaloes that were kept on pasture of $B$. brizantha for about four years; and as a negative control, 10 buffaloes that were maintained on native pasture without Brachiaria spp. since birth. Fourteen lectins were tested (Con-A, SBA, WGA, DBA, UEA, RCA, PNA, GSL-I, PSA, LCA, PHA-E, PHA-L, SJA and SWGA), in a total of 1120 evaluated samples. Previous studies demonstrated that PNA showed great binding reactivity for foamy macrophages in cattle and sheep. In the present study, SWGA showed high specificity and marked binding reactivity for foamy macrophages; WGA, GSL, PHA-E and PHA-L showed moderate to marked reactivity, but low specificity for foamy macrophages. The other lectins had not relevant reactivity or specificity. Moreover there was no relevant reactivity difference between the collected samplesd from buffaloes that grazed B. decumbens for 12 months and Brachiaria brizantha for 18 months. However the decreased presence of foamy macrophages and its lectin histochemical binding in animals that fed on B. brizantha for a longer time, indicates
\end{abstract}

\footnotetext{
${ }^{1}$ Recebido em 15 de março de 2016.

Aceito para publicação em 17 de junho de 2016.

${ }^{2}$ Curso de Pós-Graduação em Medicina Veterinária, Instituto de Veterinária, Universidade Federal Rural do Rio de Janeiro (UFRRJ), BR-465 Km 7, Seropédica, RJ 23890-000, Brasil. Pesquisa de Mestrado com apoio da CAPES. *Autor para correspondência: ileanamiranda@gmail.com

${ }^{3}$ Faculdade de Veterinária, Universidade Federal do Pará (UFPA), Avenida dos Universitários s/n, Castanhal, PA 68746-360, Brasil.
} 
that the buffaloes can pass through an adaptation process according to the plant intake time. Lectin histochemistry analysis can be used to characterize the material stored in foamy macrophages present in liver and mesenteric lymph node of buffaloes that graze on Brachiaria spp. pastures and helps to clarify the pathogenesis of these cells.

INDEX TERMS: Lectin histochemistry, liver, mesenteric lymph node, buffaloes, Brachiaria spp., saponins.

RESUMO.- Animais que se alimentam em pastos de Brachiaria spp. comumente apresentam macrófagos espumosos isolados ou agrupados no fígado, além de cristais no interior de ductos biliares. A patogênese da formação e a natureza do material armazenado nestas células, contudo, ainda não são completamente conhecidas. Através da avaliação lectino-histoquímica, saponinas esteroidais (metabólitos glicosilados secundários) têm sido identificadas nos cristais e no citoplasma das células espumosas, e provavelmente são responsáveis por danificar o fígado e levar ao acúmulo de filoeritrina. Por meio deste trabalho, objetivou-se padronizar e caracterizar a utilização da lectino-histoquímica na detecção de metabólitos glicosilados nos tecidos de búfalos mantidos em diferentes pastos de Brachiaria spp. no Brasil. Fragmentos de fígado e linfonodo mesentérico de 40 animais foram analisados: 10 búfalos mantidos em pastagem predominante de $B$. decumbens por aproximadamente 12 meses; 10 búfalos mantidos em pastagem predominante de $B$. brizantha por aproximadamente 18 meses; 10 búfalos mantidos em pastagem de $B$. brizantha por aproximadamente quatro anos; e, como controle negativo, 10 búfalos mantidos em pastagem livre de Brachiaria spp. desde o nascimento. Quatorze lectinas foram testadas (Con-A, SBA, WGA, DBA, UEA, RCA, PNA, GSL-I, PSA, LCA, PHA-E, PHA-L, SJA e SWGA), em um total de 1120 fragmentos avaliados. Estudos anteriores demonstraram que a lectina PNA possui marcada reatividade para macrófagos espumosos de bovinos e ovinos. No presente estudo, a lectina SWGA apresentou acentuada reatividade e alta especificidade para macrófagos espumosos; WGA, GSL, PHA-E e PHA-L mostraram moderada a acentuada reatividade, mas baixa especificidade aos macrófagos espumosos; as outras lectinas não apresentaram reatividade ou especificidade relevantes. Além disso, não houve diferença relevante de marcação entre os fragmentos coletados de animais que se alimentaram de $B$. decumbens por 12 meses e B. brizantha por 18 meses. Porém, a diminuição da presença e marcação lectino-histoquímica dos macrófagos espumosos nos tecidos dos búfalos que ingeriram Brachiaria brizantha durante mais tempo indica que os animais podem passar por um processo de adaptação de acordo com o tempo de ingestão da planta. A avaliação lectino-histoquímica pode ser utilizada para caracterizar o material armazenado em macrófagos espumosos presentes no fígado e linfonodo mesentérico de búfalos que se alimentam em pastagens de Brachiaria spp. e ajuda na compreensão da patogênese de formação destas células.

TERMOS DE INDEXAÇÃO: Lectino-histoquímica, fígado, linfonodo mesentérico, búfalos, Brachiaria spp., saponinas.

\section{INTRODUÇÃO}

No Brasil, surtos de fotossensibilização hepatógena causada pela ingestão de Brachiaria spp. em bovinos, ovinos e, por vezes, em caprinos e búfalos determinam perdas econômicas significativas, especialmente pela queda da produtividade dos animais afetados (Tokarnia et al. 2012). Desde 1985, autores têm sugerido que a toxicidade da Brachiaria se deve à presença de saponinas esteroidais litogênicas na gramínea, que são metabólitos glicosilados secundários possivelmente responsáveis por causar lesão hepática e consequente acúmulo de filoeritrina (Opasina 1985, Riet-Correa et al. 2011). Entretanto, a formação e o tipo de material armazenado nos macrófagos espumosos presentes no fígado de animais mantidos em pastos de Brachiaria spp. ainda não são completamente conhecidos.

Considerando a importância da bubalinocultura para a região Norte do Brasil, assim como o fato de que as principais forrageiras introduzidas nesta região são diferentes espécies de Brachiaria, Riet-Correa et al. (2010) avaliaram fragmentos de fígado e linfonodo mesentérico de búfalos previamente mantidos em pastos de Brachiaria spp. As alterações nos hepatócitos encontravam-se principalmente na região centrolobular e eram mais acentuadas nas áreas com maior infiltração de macrófagos espumosos, assim como nas áreas de fibrose capsular (Riet-Correa et al. 2010).

Em estudos anteriores, por meio de avaliação lectino-histoquímica, foi possível detectar glicoconjugados em macrófagos espumosos nos tecidos de bovinos (Gomar et al. 2005) e ovinos (Boabaid et al. 2011, Costa et al. 2013) que se alimentavam de Brachiaria spp. Através deste trabalho, objetivou-se padronizar a utilização da lectino-histoquímica na detecção de glicoconjugados nos tecidos de búfalos mantidos em diferentes pastos de Brachiaria spp. no Brasil, verificar se há diferença de reatividade dos macrófagos espumosos às lectinas nas diferentes espécies de Brachiaria (B. decumbens e B. brizantha) e descrever, pela primeira vez, os achados lectino-histoquímicos em fígado e linfonodo mesentérico de búfalos mantidos em pastos de Brachiaria spp.

\section{MATERIAL E MÉTODOS}

Amostras. 0 exame lectino-histoquímico foi realizado em fragmentos de fígado e linfonodo mesentérico, previamente fixados em formalina a $10 \%$ e incluídos em parafina, de 40 búfalos (Bubalus bubalis) da raça Murrah, sexo não informado, sem sinais clínicos de fotossensibilização, provenientes do estudo desenvolvido por Riet-Correa et al. (2010). Destes animais, 10 búfalos, com idade entre 24 e 30 meses, foram mantidos em pastagem predominante de Brachiaria decumbens por aproximadamente 12 meses, em 
uma propriedade localizada no município de Ourém, PA; 10 búfalos, com idade não informada, foram mantidos em pastagem com predominância de Brachiaria brizantha por aproximadamente 18 meses, em propriedade localizada no município de Paragominas, PA; e 10 búfalos com idade entre três e quatro anos, provenientes do município de Rondon do Pará, PA, foram criados desde o nascimento em uma propriedade que utilizava somente $B$. brizantha na alimentação. Como controle negativo, foram utilizados fragmentos de fígado e linfonodo mesentérico de outros 10 búfalos, de três a quatro anos de idade, provenientes da Ilha de Marajó, PA, e mantidos em pastagem de campo nativo, livre de Brachiaria spp. desde o nascimento.

Avaliação lectino-histoquímica. Foram utilizadas as lectinas Canavalia ensiformis agglutinin (Con-A), Dolichos biflorus agglutinin (DBA), Glycine max agglutinin (SBA), Arachis hypogaea agglutinin (PNA), Ricinus communis agglutinin-I (RCA-I), Ulex europaeus agglutinin-I (UEA-I), Triticum vulgaris agglutinin (WGA), Succinyl-WGA (SWGA), Griffonia (Bandeiraea) simplicifolia-I (GSL-I), Sophora japonica (SJA), Pisum sativum (PSA), Phaseolus vulgaris (PHA-L e PHA-E), Lens culinaris ou L. esculenta (LCA) (Lectin Kit Biotinylated BK 1000 e 2000, Vector Laboratories Inc., Burlingame, CA, 94010, USA).

Seções histológicas cortadas a $5 \mu \mathrm{m}$ de espessura de fígado e linfonodo mesentérico foram fixadas em lâminas silanizadas, desparafinadas em xilol, hidratadas em álcool e incubadas em duas soluções de peróxido de hidrogênio a 3\% por 15 minutos cada para bloqueio de peroxidases endógenas. Após a lavagem das lâminas por dois minutos com tampão fosfato (PBS), estas ficaram submersas em tampão citrato $(\mathrm{pH} \mathrm{6,0)}$ para recuperação antigênica por 30 minutos em banho-maria a $98^{\circ} \mathrm{C}$. 0 bloqueio de reações inespecíficas foi realizado com leite desnatado a 5\% (Moli$\mathrm{Co}^{\circledR}$ - Indústria Brasileira) por 30 minutos. Os cortes foram incubados "overnight" com lectinas na diluição de $5 \mu \mathrm{g} / \mathrm{mL}$ em PBS, com exceção da lectina Con-A $(1,0 \mu \mathrm{g} / \mathrm{mL})$ e RCA-I $(0,5 \mu \mathrm{g} / \mathrm{mL})$. Posteriormente, as amostras foram incubadas com o complexo avidina-biotina-peroxidase (Vector Laboratories Inc.) por 20 minutos. Todas as seções foram coradas com o cromógeno diaminobenzidina (DAB), contra-coradas com hematoxilina de Harris e montadas para avaliação em microscópio óptico.

Cada uma das 14 lectinas foi testada em dois fragmentos (fígado e linfonodo mesentérico) de 40 búfalos, totalizando 1120 fragmentos avaliados. A marcação lectino-histoquímica foi graduada como leve $(+)$, moderada $(++)$ ou acentuada $(+++)$, de acordo com a intensidade da reatividade de ligação das lectinas. Após a análise dos resultados, calculou-se a média da intensidade de reação das lectinas e a porcentagem de fragmentos que apresentaram marcação para as seguintes estruturas: macrófagos, membrana de hepatócitos, grânulos citoplasmáticos de hepatócitos, ductos biliares, células de Kupffer, capilares sinusoides, endotélio, plasmócitos, neutrófilos e células da região centro-folicular.

\section{RESULTADOS}

A análise lectino-histoquímica revelou que a lectina SWGA apresentou acentuada reatividade e alta especificidade

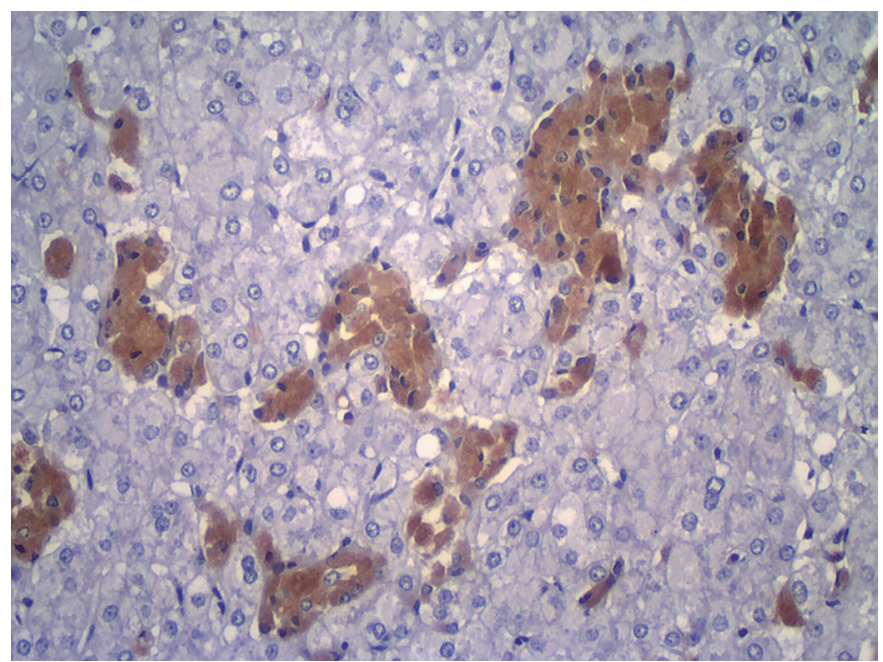

Fig.1. Fígado de búfalo mantido em pastagem de Brachiaria brizantha por 18 meses. Acentuada marcação e alta especificidade para a lectina SWGA em macrófagos espumosos. Hematoxilina de Harris, obj.20x.

para os macrófagos espumosos presentes no fígado (Fig.1) e linfonodo mesentérico (Fig.2) dos animais que se alimentaram de Brachiaria decumbens por 12 meses e Brachiaria brizantha por 18 meses. Não foram encontradas diferenças relevantes de reatividade ou especificidade nos cortes histológicos entre os búfalos destes dois grupos. Nos animais mantidos em pastagem de $B$. brizantha por aproximadamente quatro anos, porém, a presença de macrófagos espumosos e a reatividade de ligação lectino-histoquímica foram notavelmente menores, com variação de intensidade de marcação leve a acentuada em apenas 30\% dos tecidos avaliados, bem como moderada reatividade aos ductos biliares em $40 \%$ dos fragmentos de fígado analisados (Quadro 1). As lectinas WGA (Fig.3 e 4), GSL-I, PHA-E e PHA-L apresentaram moderada a acentuada reatividade aos macrófagos espumosos, além de leve a moderada reatividade às células inflamatórias e estruturas hepáticas e vasculares. No grupo controle, as lectinas WGA, GSL-I, PHA-E e PHA-L apresentaram de leve a moderada reatividade às células inflamatórias e estruturas hepáticas e vasculares. As demais lectinas não apresentaram reatividade ou especificidade relevantes.

\section{DISCUSSÃO}

Embora estudos similares de detecção de glicoconjugados já tenham sido realizados em tecidos de animais de outras espécies, este trata-se do primeiro estudo lectino-histoquímico realizado em bubalinos que se alimentaram de Brachiaria spp. Em bovinos sem fotossensibilização mantidos em pastos de Brachiaria decumbens e Brachiarioa brizantha, as lectinas PNA, WGA e SBA demonstraram maior afinidade pelos macrófagos espumosos (Gomar et al. 2005). Em ovinos sem fotossensibilização que se alimentavam exclusivamente de Brachiaria spp., as lectinas Con-A, RCA-I, WGA, LCA e PHA-L foram as que apresentaram maior reatividade em macrófagos espumosos (Boabaid et al. 2011). Em ovinos com fotossensibilização mantidos em pastagem 
de B. decumbens, as lectinas PNA, WGA, SBA, GSL-I e LCA mostraram melhor afinidade de ligação com macrófagos espumosos (Costa et al. 2013).

No presente estudo, dentre as 14 lectinas testadas, a SWGA apresentou acentuada reatividade e revelou-se como a mais específica para a marcação dos macrófagos espumosos, que são células que provavelmente contêm saponinas esteroidais misturadas a restos de hepatócitos fagocitados após degenerarem ou necrosarem em decorrência do excesso destas substâncias (Driemeier et al. 1999). Dos três estudos de avaliação lectino-histoquímica em tecidos de animais mantidos em pastagens de Brachiaria spp. citados anteriormente, apenas o mais recente testou a lectina SWGA em tecidos de ovinos (Costa et al. 2013). No referido trabalho, entretanto, esta lectina apresentou apenas leve reatividade e baixa especificidade para os macrófagos es- pumosos, um resultado não considerado relevante. Além da diferença entre as espécies dos animais utilizados no presente estudo e no de Costa et al. (2013) que, possivelmente, já pode influenciar no metabolismo dos glicoconjugados e na consequente marcação lectino-histoquímica, deve considerar-se, também, que os ovinos do estudo anterior apresentavam fotossensibilização, uma condição ausente nos búfalos deste trabalho. Pelo fato dos estudos de Gomar et al. (2005) e Boabaid et al. (2011) não terem avaliado a lectina SWGA, não é possível estabelecer maiores comparações acerca da diferença de reatividade desta lectina.

Em contraste, alguns dos estudos de avaliação lectino-histoquímica em animais intoxicados por Brachiaria spp, previamente reportados, revelaram alta especificidade dos macrófagos espumosos à lectina PNA, com acentuada rea-
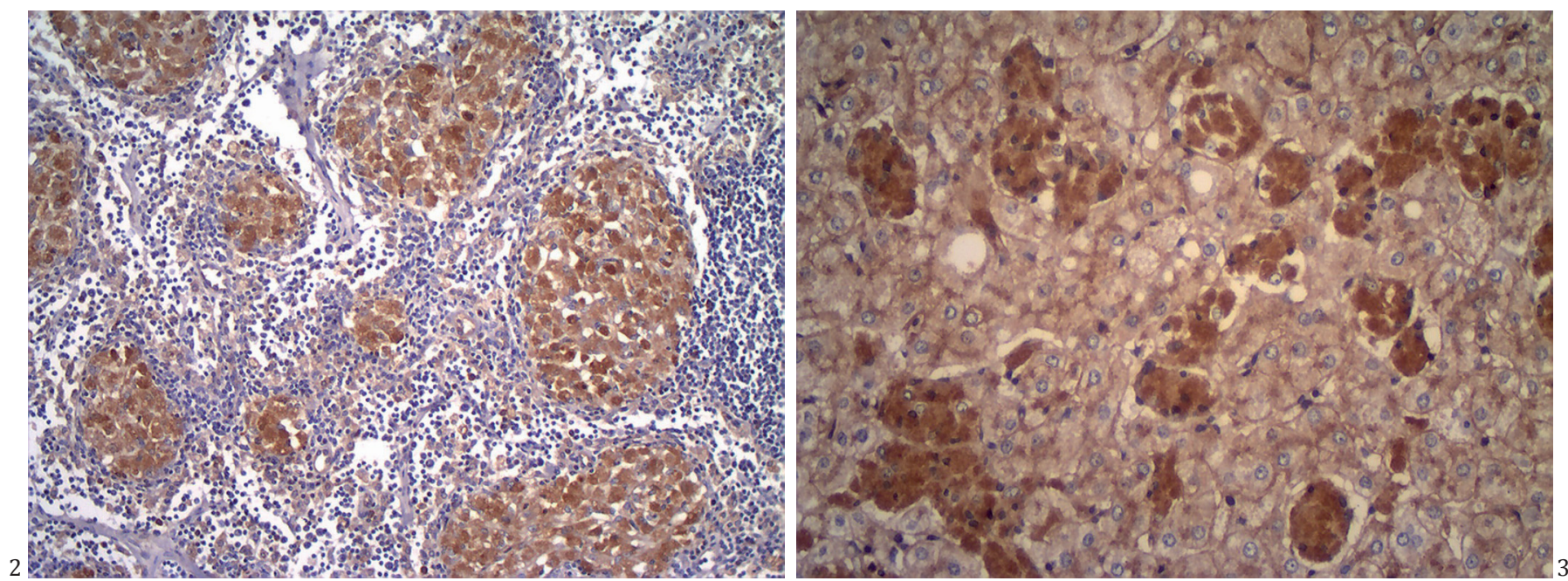

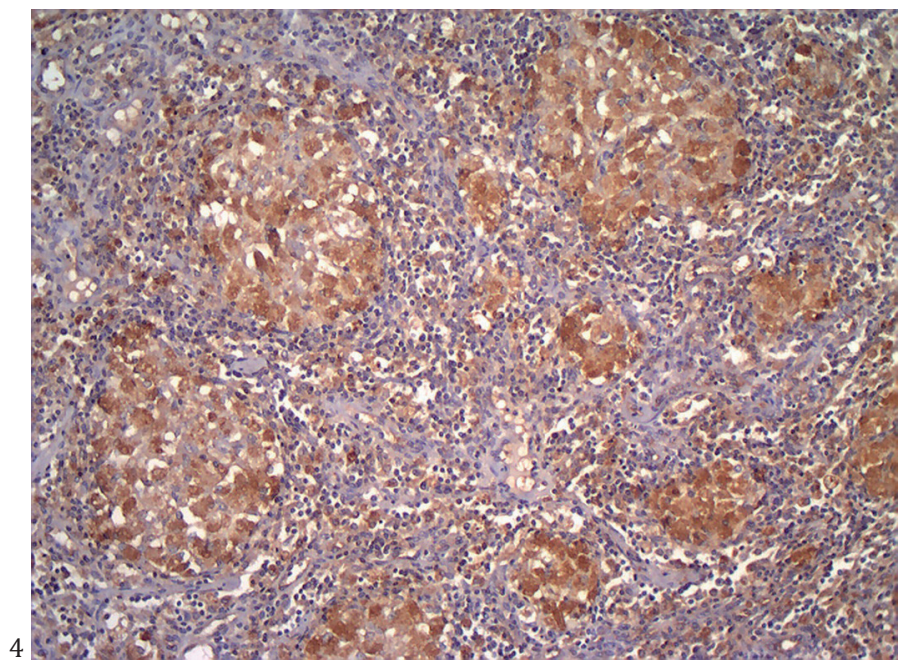

Fig.2. Linfonodo mesentérico de búfalo mantido em pastagem de Brachiaria brizantha por 18 meses. Acentuada marcação para a lectina SWGA em macrófagos espumosos em folículos. Hematoxilina de Harris, obj.10x.

Fig.4. Linfonodo mesentérico de búfalo mantido em pastagem de Brachiaria brizantha por 18 meses. Acentuada marcação e baixa especificidade (outras estruturas também marcadas) para a lectina WGA em macrófagos espumosos em folículos. Hematoxilina de Harris, obj.10x.

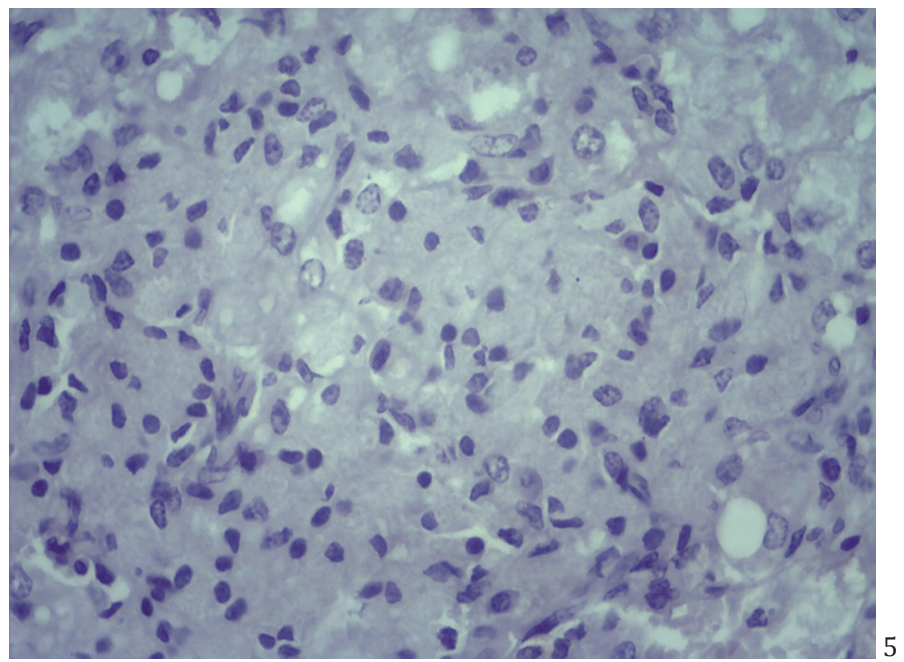

Fig.3. Fígado de búfalo mantido em pastagem de Brachiaria brizantha por 18 meses. Acentuada marcação e baixa especificidade (outras estruturas também marcadas) para a lectina WGA em macrófagos espumosos. Hematoxilina de Harris, obj.20x.

Fig.5. Fígado de búfalo mantido em pastagem de Brachiaria brizantha por 18 meses. Ausência de marcação para a lectina PNA em macrófagos espumosos. Hematoxilina de Harris, obj.20x. 


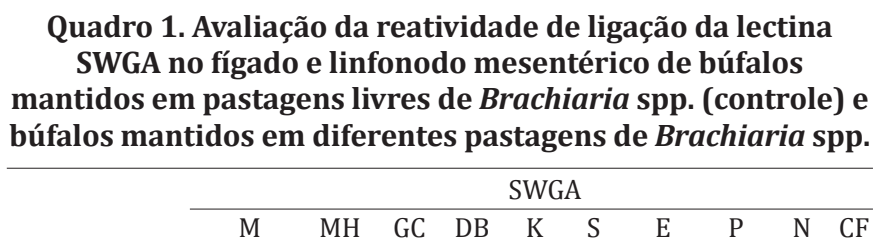

\begin{tabular}{|c|c|c|c|c|c|c|c|c|c|}
\hline Controle & - & - & - & - & - & - & - & - & - \\
\hline Negativo & & & & & & & & & \\
\hline B. decumbens & $++/+++$ & & & & & & & & \\
\hline (12 meses) & $100 \%$ & - & - & - & - & - & - & - & - \\
\hline B. brizantha & $++/+++$ & & & & & & & & \\
\hline (18 meses) & $100 \%$ & - & - & - & - & - & - & - & - \\
\hline $\begin{array}{l}\text { B. brizantha } \\
\text { (4 anos) }\end{array}$ & $\begin{array}{c}+/+++ \\
30 \%\end{array}$ & - & - & $\begin{array}{c}++ \\
40 \%\end{array}$ & - & - & - & - & - \\
\hline
\end{tabular}

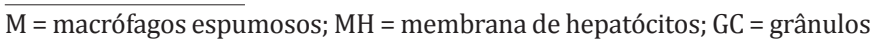
citoplasmáticos de hepatócitos; $\mathrm{DB}=$ ductos biliares; $\mathrm{K}=$ células de $\mathrm{Ku}$ pffer; $\mathrm{S}$ = capilares sinusoides; $\mathrm{E}$ = endotélio; $\mathrm{P}=$ plasmócitos; $\mathrm{N}=$ neutrófilos; $\mathrm{CF}=$ células da região centro-folicular; +++ reatividade acentuada; ++ reatividade moderada, + reatividade leve, - ausência de reatividade.

tividade nos estudos de Gomar et al. (2005) e Costa et al. (2013). Na avaliação de Boabaid et al. (2011) houve apenas leve reatividade, enquanto no presente trabalho a PNA não reagiu com os macrófagos espumosos dos animais avaliados (Fig.5).

Não se sabe, ainda, a que exatamente atribuir a diferença de reatividade de ligação aos macrófagos espumosos, mas é possível que a natureza do material acumulado possa variar em função da fase de crescimento da planta, ou de acordo com o tipo e a proporção de glicoconjugados armazenados nas plantas em decorrência da época do ano. Sabe-se que, dependendo da espécie animal, o fígado pode reagir de maneiras diferentes à ingestão de uma mesma substância tóxica devido a particularidades no metabolismo da espécie do animal em questão. Por exemplo, equinos com fotossensibilização causada pela ingestão de $B$. humidicola não apresentam os típicos macrófagos espumosos encontrados no fígado de ruminantes intoxicados, e imagens negativas de cristais no interior de ductos biliares raramente estão presentes (Barbosa et al. 2006). Apesar de também serem sensíveis à intoxicação por Brachiaria spp., os bubalinos são mais resistentes que os bovinos e, devido ao fato de comumente não apresentarem fotossensibilização, mesmo com acentuada gravidade de lesões hepáticas, são considerados animais resilientes à intoxicação pela gramínea (Riet-Correa et al. 2010). É possível, também, que a pelagem escura dos búfalos possua um papel importante neste processo ao proporcionar maior proteção da pele aos raios ultravioleta. Sugere-se, ainda, que diferenças de reatividade às lectinas também possam ocorrer de acordo com a presença ou não de fotossensibilização, da evolução clínica e do tempo de ingestão dos glicoconjugados (Costa et al. 2013).

Apesar da baixa especificidade e da maior variação de intensidade, as lectinas WGA, GSL-I, PHA-E e PHA-L reagiram com os macrófagos espumosos dos búfalos do presente trabalho. Estas lectinas, porém, foram consideradas de menor especificidade por também reagirem, mesmo que em menor grau, com células inflamatórias e com a maioria das estruturas hepáticas e vasculares. Já foi sugerido que uma menor reatividade aos hepatócitos indica menor quantidade de glicoconjugados em comparação aos macrófagos ou, alternativamente, que os resíduos/produtos da degradação celular (organoides) induzida pelos glicoconjugados sejam mais abundantes nos macrófagos (Costa et al. 2013). A acentuada reatividade da lectina WGA aos macrófagos espumosos, também verificada nos três estudos lectino-histoquímicos anteriores (Gomar et al. 2005, Boabaid et al. 2011, Costa et al. 2013) indica que, independentemente da espécie - bovina, ovina ou bubalina -, para efeito de diagnóstico, os macrófagos espumosos que se formam no fígado, em consequência da ingestão prolongada de saponinas esteroidais são positivos para esta lectina. A lectina GSL-I foi testada apenas por Costa et al. (2013), que reportaram forte reatividade. As lectinas PHA-L, avaliadas por Costa et al. (2013) e Boabaid et al. (2011), e PHA-E, analisada apenas por Costa et al. (2013), revelaram uma grande variação de intensidade e baixa especificidade para os macrófagos espumosos, também com variedade de marcação para as células hepáticas.

No presente trabalho, não foram observadas diferenças na intensidade de marcação dos macrófagos espumosos entre os respectivos fragmentos de fígado e linfonodo mesentérico dos búfalos de cada grupo. Embora existam relatos de que a concentração da saponina esteroidal protodioscina é significativamente maior na $B$. decumbens do que em B. brizantha (Lima et al. 2009), não houve diferença relevante de reatividade ou especificidade lectino-histoquímica entre os búfalos do presente estudo que foram mantidos em pastagens de $B$. decumbens por 12 meses e $B$. brizantha por 18 meses.

Curiosamente, nos tecidos dos búfalos que se alimentaram de $B$. brizantha por aproximadamente quatro anos, observou-se uma diminuição tanto na presença de macrófagos espumosos, quanto na intensidade de reação da lectina SWGA, com variedade de marcação leve a acentuada em apenas 30\% dos fragmentos avaliados. Por outro lado, neste mesmo grupo, houve moderada reatividade de ligação da lectina SWGA aos ductos biliares em 40\% dos fragmentos de fígado analisados. A diminuição da presença e marcação lectino-histoquímica dos macrófagos espumosos nos tecidos dos búfalos que ingeriram $B$. brizantha durante mais tempo indica que os animais podem passar por um processo de adaptação de acordo com o tempo de ingestão da planta e melhorar a capacidade de metabolização de saponinas esteroidais.

Adicionalmente, no presente estudo, as lectinas Con-A, SBA, DBA, UEA-I, RCA-I, PNA, PSA, LCA e SJA não apresentaram reatividade ou especificidade importantes para a marcação do acúmulo de glicoconjugados e seus subprodutos. A lectina DBA, contudo, mostrou-se excelente para a marcação de células inflamatórias em todos os tecidos avaliados, particularmente para plasmócitos e neutrófilos. Assim como no estudo de Costa et al. (2013), a lectina UEA-I reagiu de forma moderada a acentuada aos ductos biliares do fígado e, como esperado, não reagiu com as células endoteliais dos vasos sanguíneos, pois sabe-se que esta lectina é específica para o endotélio vascular de humanos (Alroy et al. 1987). Apesar da ampla variação de marcação e in- 
tensidade, o endotélio vascular dos búfalos deste trabalho apresentou reatividade às lectinas RCA I, PSA e LCA.

Os presentes resultados indicam que os macrófagos espumosos de búfalos mantidos em pastagens de Brachiaria spp. contêm principalmente N-Acetilglucosamina (ligação com SWGA e WGA) e, em menor quantidade, $\alpha$-D-Galactose e $\alpha$-N-Acetilgalactosamina (ligação com GSL-I) e outras estruturas mais complexas ligadas à manose (ligação com PHA-E e PHA-L). Mesmo inédito, o significado da acentuada marcação com a lectina SWGA assemelha-se parcialmente aos estudos lectino-histoquímicos em animais intoxicados por Brachiaria spp. realizados até o presente momento, que sugerem que os macrófagos espumosos contêm quantidades significativas de D-Galactose, N-Acetilgalactosamina e N-Acetilglucosamina (Gomar et al. 2005, Boabaid et al. 2011, Costa et al. 2013). É possível, porém, que, em búfalos, a quantidade de $\mathrm{N}$-acetilglucosamina seja armazenada em maiores quantidades no interior de macrófagos espumosos, de acordo com a acentuada reatividade da lectina SWGA.

Em casos de esfingomielinose (doença de Niemann-Pick), macrófagos espumosos podem estar presentes em tecidos não nervosos, como fígado, baço, pulmão, rim, adrenal, linfonodo e tonsila. Nos casos de esfingomielinose felina, o material armazenado foi positivo para Con A, RCA I e WGA (Kamiyu et al. 1991). Já a avaliação lectino-histoquímica do fígado e baço de humanos com doença de Niemann-Pick, demonstrou que as lectinas Con-A, PNA e SBA foram as que melhor reagiram com as células afetadas (Lageron 1987) e são semelhantes aos resultados de Gomar et al. (2005) e Costa et al. (2013). Este padrão lectino-histoquímico também é parcialmente comparável ao encontrado nas células espumosas em fígado e baço de humanos com doença de Hurler (uma mucopolissacaridose tipo I causada pela deficiência da enzima $\alpha$-L-iduronidase), que são positivas para PNA, WGA e TPA (Tetragonolobulus purpureus) (Faraggiana et al. 1982). Todavia, em nenhum dos estudos recém-mencionados testou-se a lectina SWGA nos tecidos avaliados.

Uma deficiência hereditária de lipase ácida lisossomal, conhecida como doença de Wolman (xantomatose familiar ou lipidose familiar de Wolman) leva ao aparecimento de células espumosas que se agregam sob a forma de ilhotas nos sinusóides do fígado, causando o acúmulo de ésteres de colesterol, colesterol livre e triglicerídeo no fígado dos indivíduos acometidos devido à diminuição da atividade dessa enzima (Kuriwaki \& Yoshida 1999). Devido ao seu comportamento anfifílico e a capacidade de formar complexos com esteroides, proteínas e fosfolipídeos de membrana, as saponinas são capazes de alterar as propriedades da membrana celular, o que altera sua permeabilidade ou causa sua destruição (Schenkel et al. 2004). Portanto, assim como já foi sugerido para bovinos e ovinos (Gomar et al. 2005, Boabaid et al. 2011, Costa et al. 2013), dadas as características morfológicas e histoquímicas dos macrófagos espumosos observados na intoxicação por Brachiaria spp. serem semelhantes às encontradas nas células espumosas na doença de Wolman, sugere-se que a inibição da lipase ácida lisossomal tam- bém possa estar envolvida na patogênese das células espumosas encontradas nos búfalos.

Em cabras com $\alpha$-manosidose, uma doença do armazenamento causada pela intoxicação por Ipomoea verbascoi$d e a$, a lectina SWGA também reage fortemente com as células de Purkinje do cerebelo, ácinos pancreáticos e células foliculares da tireoide, em um padrão lectino-histoquímico de reatividade também para Con A, WGA, LCA, PSA, PHA-E, RCA120 e PNA, o que corrobora parcialmente com os relatos anteriores de manosidose em humanos, gatos e bezerros, e intoxicação por outras plantas, tais como Ipomoea carnea subsp. fistulosa, I. sericophylla, I. riedelii, Swainsona spp, Sida carpinifolia e Tilia cordata (Mendonça et al. 2012). De fato, a semelhança entre o padrão lectino-histoquímico do material acumulado nos macrófagos espumosos de animais que se alimentam de Brachiaria spp. e nas células afetadas por doenças do armazenamento também pode indicar alguma similaridade na patogênese destas doenças. Sabe-se que a maioria das plantas responsáveis por causar doença do armazenamento lisossomal contém os alcalóides swainsonina e calesteginas como principais princípios ativos, responsáveis pela toxicidade da planta. A swainsonina é um alcalóide indolizidínico, potente inibidor da $\alpha$-manosidase lisossômica e $\alpha$-manosidase II do complexo de Golgi (Schwarz et al. 2004). A inibição destas duas enzimas pela swainsonina ocorre de forma competitiva, porém, em concentrações mais elevadas, este alcalóide inibe também a $\alpha$-glicosidase, $\beta$-glicuronidase, $\beta$-galactosidase, $\beta$-xilosidase e $\alpha$-arabinosidase (Cenci di Bello et al. 1989).

Os mecanismos moleculares envolvidos na intoxicação por Brachiaria spp. que levam ao acúmulo de glicoconjugados nos tecidos continuam desconhecidos. Presumivelmente, assim como ocorre nas doenças do armazenamento causadas por plantas que contêm swainsonina, dependendo do grau de intoxicação do animal, a inibição "em série" de um conjunto de hidrolases lisossomais relacionadas aos componentes glicosilados possa estar envolvida no processo, tais como $\mathrm{N}$-acetilglicosaminidase, $\mathrm{N}$-acetilgalactosaminidase, $\alpha$-galactosidase e $\alpha$-manosidase. É possível, ainda, que o material armazenado nas células espumosas possa se acumular devido à inibição de uma hidrolase em particular, causando lipidose lisossomal, assim como foi sugerido em casos de xantomatose familiar (Kuriwaki \& Yoshida 1999). Ou, por outro lado, ao invés de uma deficiência enzimática, o acúmulo possa ser resultado da formação de complexos de lipídeos resistentes ao metabolismo por modificações primárias no retículo endoplasmático (Gomar et al. 2005).

São necessários estudos aprofundados de avaliação lectino-histoquímica em conjunto com outros testes bioquímicos e histoquímicos para caracterizar completamente as lesões hepáticas causadas pela intoxicação por Brachiaria spp. A patogenia desta enfermidade ainda não foi esclarecida e a sua complexidade demanda a utilização de metodologias com maior controle de variáveis, tais como a padronização dos animais em questão (espécie, raça, sexo e idade), da pastagem (espécie, variedade, estágio de desenvolvimento, época do ano e duração do pastejo) e do teste de avaliação das amostras. 


\section{CONCLUSÕES}

A lectina SWGA apresentou acentuada reatividade e especificidade para macrófagos espumosos no fígado e linfonodo mesentérico de búfalos que se alimentaram em diferentes pastos de Brachiaria spp.

Não houve diferença relevante de reatividade ou especificidade lectino-histoquímica aos macrófagos espumosos entre os búfalos que foram mantidos em pastagens de Brachiaria decumbens por 12 meses e $B$. brizantha por 18 meses.

A diminuição da presença e marcação lectino-histoquímica dos macrófagos espumosos nos tecidos dos búfalos que ingeriram $B$. brizantha durante mais tempo indica que os animais podem passar por um processo de adaptação, de acordo com o tempo de ingestão da planta.

A avaliação lectino-histoquímica pode ser utilizada para caracterizar o material armazenado em macrófagos espumosos presentes em búfalos que se alimentam em pastagens de Brachiaria spp. e ajudar na compreensão da patogênese de formação destas células.

Agradecimentos.- À Letícia Baptista Pinto pelo apoio técnico, ao CNPq (Proc. 311606/2012-1) pelo suporte financeiro para a compra dos anticorpos, à FAPERJ (Proc. E-26/110.602/2014) pelo auxílio financeiro para a compra das lectinas, e à CAPES pela bolsa de mestrado da primeira autora.

\section{REFERÊNCIAS}

Alroy J., Goyal V. \& Skutelsky E. 1987. Lectin histochemistry of mammalian endothelium. Histochemistry 86:603-607.

Barbosa J.D., Oliveira C.M.C., Tokarnia C.H. \& Peixoto P.V. 2006. Fotossensibilização hepatógena em eqüinos pela ingestão de Brachiaria humidicola (Gramineae) no Estado do Pará. Pesq. Vet. Bras. 26(3):147-153.

Boabaid F.M., Antoniassi N.A.B., Pescador C.A., Souza M.A., Gasparetto N.D., Cruz C.E.F., Bezerra Júnior P.S., Driemeier D. \& Colodel E.M. 2011. Lectin histochemistry on sections of liver and hepatic lymph nodes from sheep grazing on Brachiaria spp., p.124-128. In: Riet-Correa F., Pfister J., Schild A.L. \& Wierenga T. (Eds), Poisoning by Plants, Mycotoxins and Related Toxins. CAB International, London.

Cenci di Bello I., Fleet G., Namgoong S.K., Tadano K. \& Winchester B. 1989. Structure-activity relationship of swainsonine. Biochem J. 259:855-861.

Costa S.Z.R., Nespoli P.B., Bezerra Júnior P.S., Nogueira V.A., Driemeier D., Boabaid F.M., Peixoto P.V., Armién A.M. \& França T.N. 2013. Avaliação lectino-histoquímica de fígado e rim de ovinos com fotossensibilização causada por Brachiaria decumbens. Pesq. Vet. Bras. 33(8):955-962.
Driemeier D., Döbereiner J., Peixoto P.V. \& Brito M.F. 1999. Relação entre macrófagos espumosos ("foam cells") no fígado de bovinos e ingestão de Brachiaria spp. no Brasil. Pesq. Vet. Bras. 19(2):79-83.

Faraggiana T., Shen S., Childs C., Strauss L. \& Churg J. 1982. Histochemical study of Hurler's disease by the use of peroxidase-labelled lectins. Histochem J. 14:655-664.

Gomar M.S., Driemeier D., Colodel E.M. \& Gimeno E.J. 2005. Lectin Histochemistry of foam cells in tissues of cattle grazing Brachiaria spp. J. Vet. Med. 52:18-21.

Kamiyu S., Yamagami T., Umeda M., Sugiyama M. \& Daigo M. 1991. Lectin histochemistry of foamy cells in non-nervous tissues of feline sphingomyelinosis. J. Comp. Pathol. 105:241-245.

Kuriwaki K. \& Yoshida H. 1999. Morphological characteristics of lipid accumulation in liver-constituting cells of acid lipase deficiency rats (Wolman's disease model rats). Pathol. Int. 49:291-297.

Lageron A. 1987. Characterization by lectin binding of the sugar moiety of glycocompounds stored in inherited diseases. Histochem. J. 19:419-425.

Lima F.G., Ribeiro C.S., Andrade D.F., Guimarães V.Y., Wysocki Júnior H.L., Haraguchi M. \& Fioravanti M.C.S. 2009. Braquiária: fatores que interferem nos níveis de saponina. Ciênc. Anim. Bras. 14(4):367-372.

Mendonça F.S., Albuquerque R.F., Evencio-Neto J., Freitas S.H., Doria R.G., Boabaid F.M., Driemeier D., Gardner D.R., Riet-Correa F. \& Colodel E.M. 2012. Alpha-mannosidosis in goats caused by the swainsonine-containing plant Ipomoea verbascoidea. J. Vet. Diagn. Invest. 24:90-95.

Opasina B.A. 1985. Photosensitization jaundice syndrome in West African dwarf sheep and goats grazed on Brachiaria decumbens. Trop. Grasslands 19:120-123.

Riet-Correa B., Riet-Correa F., Oliveira Junior C.A., Duarte V.C. \& Riet-Correa G. 2010. Alterações histológicas em fígados e linfonodos de búfalos (Bubalus bubalis) mantidos em pastagens de Brachiaria spp. Pesq. Vet. Bras. 30(9):705-711.

Riet-Correa B., Castro M.B., Lemos R.A.A., Riet-Correa G., Mustafa V. \& Riet-Correa F. 2011. Brachiaria spp. poisoning of ruminants in Brazil. Pesq. Vet. Bras. 31(3):183-192.

Schenkel E.P., Gosmann G. \& Athayde M.L. 2004. Saponinas, p.711-740. In: Simões C.M.O., Schenkel E.P., Gosmann G., Melo J.C.P., Mentz L.A. \& Petrovick P.R. (Eds), Farmacognosia da Planta ao Medicamento. UFRGS, Porto Alegre.

Schwarz A., Hosomi R.Z., Henrique B.S., Hueza I., Gardner D., Haraguchi M., Gorniak S.L., Bernardi M.M. \& Spinosa H.S. 2004. Identificação de princípios ativos presentes na Ipomoea carnea brasileira. Revta Bras. Ciênc. Farm. 40(2):181-187.

Tokarnia C.H., Brito M.F., Barbosa J.D., Peixoto P.V. \& Döbereiner J. 2012. Plantas Tóxicas do Brasil para Animais de Produção. 2르 ed. Helianthus, Rio de Janeiro. 566p. 